\title{
When similar ecological patterns in time emerge from different initial conditions: equifinality in the breeding performance of animal populations
}

\author{
Vincenzo Penteriani \\ Department of Conservation Biology, Estación Biológica de Doñana, CSIC, Avda, María Luisa s/n, Pabellón del Perú, 41013 Seville, Spain
}

Keywords:

Equifinality

Ecological pattern formation in time

Fecundity

Animal populations a b s t r a c t

In many behavioural, ecological and evolutionary trade-offs, patterns and trends, the same/ similar outcomes are often expected from the different initial conditions. One of the most frequently encountered problems in ecology is how to disentangle two or more different hypotheses possibly explaining the emergence of an ecological pattern based on limited data that would fit both. Using previously published interaction patterns between floaters and breeders of an eagle population (Penteriani et al., 2006), it was possible to detect and to find an explanation to the singular case of the emergence of a similar ecological pattern under two very different scenarios, that is when different factors are affecting the intrinsic dynamic of a population.
1.

Introduction

Population ecologists are interested in the mechanisms behind any observed pattern and pattern formation can play a very important role in ecological and evolutionary systems. However, we can be recurrently confronted to complicated dynamics and fuzzy distribution patterns (Savill and Hogeweg, 1999; Nowak and May, 1992; Nowak and Sigmund, 2000). In fact, one of the most frequently encountered problems in ecology is how to disentangle two or more different hypotheses possibly explaining the emergence of an ecological pattern based on limited data that would fit both. On one hand, the analysis of the spatio-temporal patterns in population dynamics calls for a large amount of data, which are seldom available (Sundell et al., 2004). On the other, several examples in the scientific literature show that frequently several distinct factors, as well as their interaction, may determine similar patterns that made interpreting patterns difficult (e.g. Bolker and Pacala, 1997; Ranta et al., 1998; Bjørnstad et al., 1999; Ruetz et al., 2005; Heath, 2006).

Equifinality is a concept strictly related to inferential fallacy (Alker, 1969), quite relevant to, but probably often overlooked by, analyses on animal population dynamics and regulation when they deduce individual processes from wide patterns. Not surprisingly, mistakes may arise from inferring processes or patterns at one level of analysis from those occurring at another level.

Equifinality has been invoked in many fields, e.g. biophysics (Bartsev and Bartseva, 2002), geosciences (Haines-Young and Petch, 1983; Schulz et al., 1999; Savenije, 2001; Sleewaegen

E-mail address: penteriani@ebd.csic.es. 


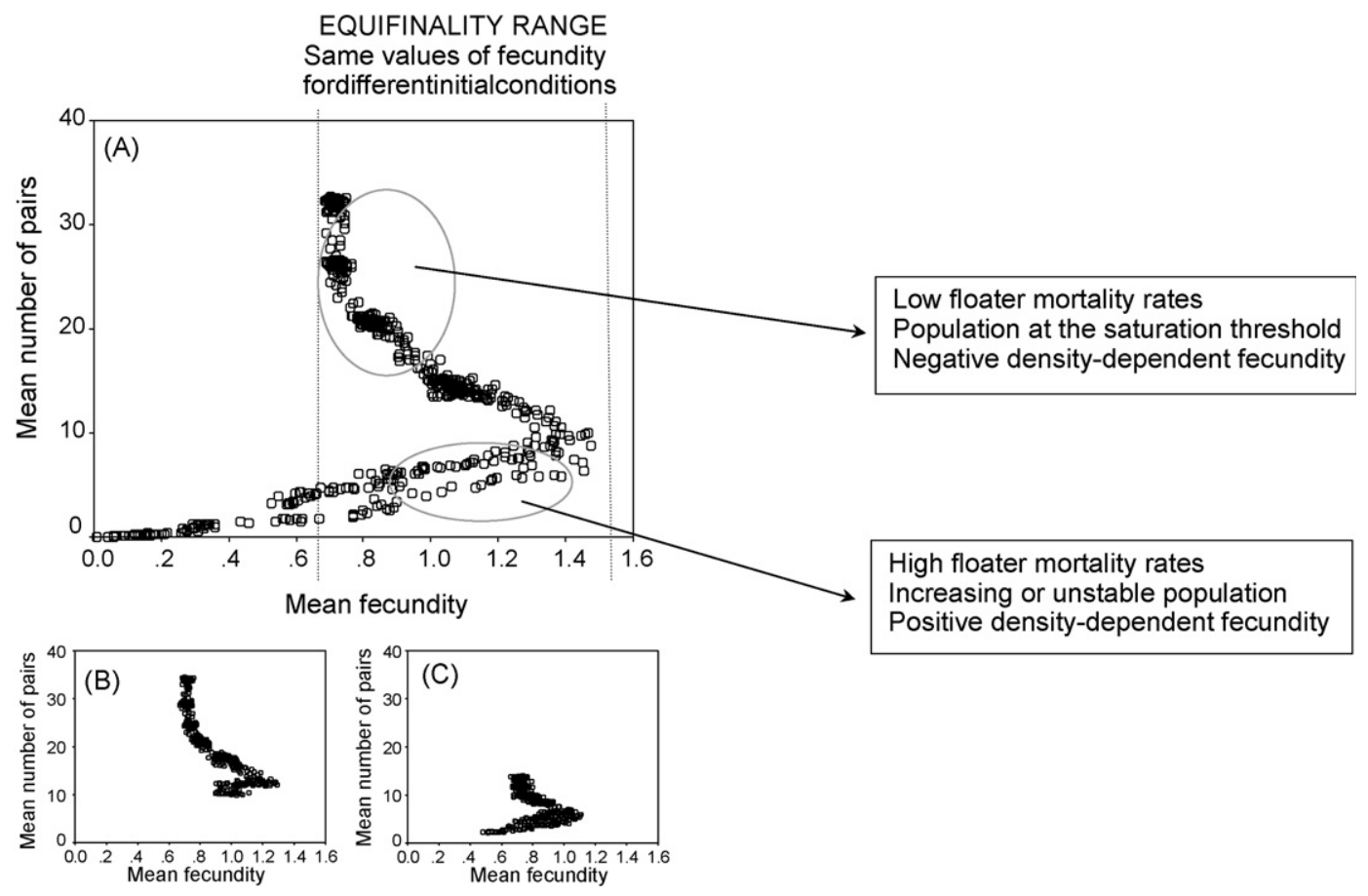

Fig. 1 - Equifinality in breeding performance, that is, different departure conditions of a breeding population can determine similar breeding performances. The examples (patterns of breeder fecundity under different levels of floater mortality; from Penteriani et al., 2006) highlight that the same values of mean fecundity can appear in the same breeding population under extremely different situations (e.g. saturated and stable population vs. increasing or unstable population), due to variations of levels of floater mortality within settlement areas. Circles in (A) indicate two of the most extreme cases, in which the population shows the same fecundity at very different population densities (more than 20 pairs vs. less than 10 pairs). (B) (population with the age at first reproduction of 3 years and 20 breeding pairs) and (C) (population with the age at first reproduction of 5 years and 10 breeding pairs) show two additional cases in which similar patterns in breeding performance may arise under different biological scenarios, i.e. when simulating different ages at first reproduction and population thresholds.

et al., 2003; Wilby, 2005), the life cycles of parasites (Gulyaev, 1997), physiology (Popescu and Rymer, 2000; Hinder and Milner, 2003; Feldman and Latash, 2005), psychology (Santoro et al., 1997; Mathieu et al., 2005) and zooarchaeology (Marean et al., 1992). For all these field, the concept of equifinality was associated to the idea that both: (a) a pattern, a trend or a shape can have different origins, i.e. can be the result of different causes, combinations of parameters, factors or pressures and (b) the end result is the same independently of the causes or stimuli that engendered it (e.g. movement end points are unaffected by either different perturbations or by variations in the starting point of the motion; Popescu and Rymer, 2000). Similarly, human medicine appeals to equifinality when the same symptomatic or syndromatic clinical diagnostic individual can represent different initial conditions that lead to the same clinical endpoint (Avissar and Schreiber, 2002). As an end result, and as recently highlighted by Beven (2006), the concept of equifinality allows us to focus our attention on the potential risk that “... there are many acceptable representations that cannot be easily rejected and that should be considered in assessing the uncertainty associated with predictions". For example, in the field of geomorphology (Beven, 2006), the term equifinality indicates that similar landforms might arise as a result of quite different sets of processes and histories.
Recently, the effects of the mortality of floaters (i.e. dispersing individuals able to enter as breeders in the reproductive population when a breeding territory or a potential mate - owner of a suitable breeding territory - becomes available) on the stability of a breeding population of Spanish imperial eagle Aquila adalberti were analysed by individuallybased simulation models simulations (Penteriani et al., 2005a,b, 2006). In particular, when analysing how different rates (from 5 to $30 \%$ ) of floater mortality could affect the mean fecundity of a breeding population under two different scenarios (i.e. when the gradient of the age at first reproduction varied from 3 to 5 years and for population thresholds of 10, 15 and 20 breeding pairs), the patterns shown by the density-dependent fecundity (see Penteriani et al., 2006 for more details) highlighted the occurrence of a singular phenomenon within the breeding population. In fact, fecundity showed similar values for different rates of floater mortality (i.e. different pressures acting on the population; Fig. 1, grey circles). This means that such similar values of fecundity can be the result of (at least) two different factors acting on the population: (a) a densitydependent effect due to population saturation (upper circle of Fig. 1) or (b) high mortalities acting on floaters (lower circle of Fig. 1). That is, two very different initial conditions (i.e. a stable and saturated population or high rates of floater mortality 
determining a decrease in the population) may determine similar patterns (i.e. the same values of mean fecundity) in a population. That is, equifinality (sensu von Bertalanffy, 1950) appears to be an intrinsic property of the breeding performance of animal populations. To my knowledge, this is the first time that equifinality has been detected in the breeding performance of animal populations. This result was supported by nonsignificant statistical outputs (see Penteriani et al., 2006), since no statistical analysis can distinguish between processes that are truly equifinal (von Bertalanffy, 1950).

Such an example shows us that we need to carefully take into consideration all the possible processes that can be responsible of the patterns that we observe in animal population, equifinality being able to engender mistakes in our perception of population dynamics. Above all, the possibility that equifinality could represent a new bias in our understanding of the dynamics of animal populations needs to be considered as the opportunity to move further and further in our analyses on animal populations, which could engender the opportunity to discover unsuspected factors (both intrinsic and extrinsic to a population) determining the patterns that we observe.

\section{Acknowledgements}

This paper has been greatly improved by comments from M.M. Delgado and C. Melián. During this research, V.P. was supported by a Marie Curie Fellowship of the European Community programme "Improving the Human Research Potential and the Socio-Economic Knowledge Base” under contract number HPMF-CT-2000-01098. The author is solely responsible for the information communicated and the European Commission is not responsible for any view or result expressed. The Junta de Andalucía also contributed to the financial support of part of this project.

\section{references}

Alker Jr., H.R., 1969. A typology of ecological fallacies. In: Dogan, M., Rokkan, S. (Eds.), Quantitative Ecological Analysis in the Social Sciences. MIT Press, Cambridge, pp. 69-86.

Avissar, S., Schreiber, G., 2002. Toward molecular diagnostics of mood disorders in psychiatry. Trends Mol. Med. 8, 294-300.

Bartsev, S.I., Bartseva, O.D., 2002. Symmetric structures and equifinality of evolution outcomes in simple neural network models. Dokl. Biochem. Biophys. 386, 235-238.

Beven, K., 2006. A manifesto for the equifinality thesis. J. Hydrol. $320,18-36$.

Bjørnstad, O.N., Ims, R.A., Lambin, X., 1999. Spatial population dynamics: analyzing patterns and processes of population synchrony. Trends Ecol. Evol. 14, 427-432.

Bolker, B., Pacala, S.W., 1997. Using moment equations to understand stochastically driven spatial pattern formation in ecological systems. Theor. Popul. Biol. 52, 179-197.

Feldman, A.G., Latash, M.L., 2005. Testing hypotheses and the advancement of science: recent attempts to falsify the equilibrium point hypothesis. Exp. Brain Res. 161, 91-103.

Gulyaev, V.D., 1997. Equifinality of life cycle in cestodes. Usp. Sovremennoi Biologii 117, 46-51.
Haines-Young, R.H., Petch, J.R., 1983. Multiple working hypotheses: equifinality and the study of landforms. Trans. Inst. Br. Geogr. 8, 458-466.

Heath, J.P., 2006. Quantifying temporal variability in population abundances. Oikos 115, 573-581.

Hinder, M.R., Milner, T.E., 2003. The case for an internal dynamics model versus equilibrium point control in human movement. J. Physiol. 549, 953-963.

Marean, C.W., Spencer, L.M., Blumenschine, R.J., Capaldo, S.D., 1992. Captive Hyena bone choice and destruction, the Schlepp effect and Olduvai Archeofaunas. J. Archaeol. Sci. 19, 101-121.

Mathieu, J.E., Heffner, T.S., Goodwin, G.F., Cannon-Bowers, J.A., Salas, E., 2005. Scaling the quality of teammates' mental models: equifinality and normative comparisons. J. Org. Behav. 26, 37-56.

Nowak, M.A., May, R.M., 1992. Evolutionary games and spatial chaos. Nature 359, 826-829.

Nowak, M.A., Sigmund, K., 2000. Games on grid. In: Dieckmann, U., Law, R., Metz, J.A. (Eds.), The Geometry of Ecological Interactions: Simplifying Spatial Complexity. Cambridge University Press, Cambridge, pp. 135-150.

Penteriani, V., Otalora, F., Ferrer, M., 2005a. Floater survival affects population persistence. The role of prey availability and environmental stochasticity. Oikos 108, 523-534.

Penteriani, V., Otalora, F., Sergio, F., Ferrer, M., 2005b. Environmental stochasticity in dispersal areas can explain the “'mysterious"' disappearance of breeding populations. Proc. Royal Soc. Lond. B 272, 1265-1269.

Penteriani, V., Otalora, F., Ferrer, M., 2006. Floater dynamics can explain positive patterns of density-dependence fecundity in animal populations. Am. Nat. 168, 697-703.

Popescu, F.C., Rymer, W.Z., 2000. End points of planar reaching movements are disrupted by small force pulses: an evaluation of the hypothesis of equifinality. J. Neurophysiol. 84, 2670-2679.

Ranta, E., Kaitala, V., Lundberg, P., 1998. Population variability in space and time: the dynamics of synchronous populations. Oikos 83, 376-382.

Ruetz III, C.R., Trexler, J.C., Jordan, F., Loftus, W.F., Perry, S.A., 2005. Population dynamics of wetland fishes: spatiotemporal patterns synchronized by hydrological disturbance? J. Anim. Ecol. 74, 322-332.

Santoro, J., Tisbe, M., Katsarakes, M., 1997. An equifinality model of Borderline Personality Disorder. The American Academy of Experts in Traumatic Stress, Inc. (http:// www.crisisinfo.org/article20.htm).

Savenije, H.H.G., 2001. Equifinality, a blessing in disguise? Hydrol. Proc. 15, 2835-2838.

Savill, N.J., Hogeweg, P., 1999. Competition and dispersal in predator-prey waves. Theor. Popul. Biol. 56, 243-263.

Schulz, K., Beven, K., Huwe, B., 1999. Equifinality and the problem of robust calibration in nitrogen budget simulations. Soil Sci. Soc. Am. J. 63, 1934-1941.

Sleewaegen, S., Samyn, D., Fitzsimons, S.J., Lorrain, R.D., 2003. Equifinality of basal ice facies from an Antarctic cold-based glacier. Ann. Glaciol. 37, 257-262.

Sundell, J., Huitu, O., Henttonen, H., Kaikusalo, A., Korpimäki, E., Pietiäinen, H., Saurola, P., Hanski, I., 2004. Large-scale spatial dynamics of vole populations in Finland revealed by the breeding success of vole-eating avian predators. J. Anim. Ecol. 73, 167-178.

von Bertalanffy, L., 1950. The theory of open systems in physics and biology. Science 111, 23-29.

Wilby, R.L., 2005. Uncertainty in water resource model parameters used for climate change impact assessment. Hydrol. Proc. 19, 3201-3219. 